\title{
BENEFÍCIOS FÍSICOS E MENTAIS DA MASSAGEM TERAPÊUTICA
}

Maria Darc Gonçalves Andrade ${ }^{1}$ Maria Marcilene Vieira de Jesus Pereira ${ }^{2}$ Patrícia Pegoraro Merêncio da Silva ${ }^{3}$ Renata Junqueira Pereira4

${ }^{1}$ Bacharel em Biomedicina pelo Instituto Educacional Santa Catarina / Faculdade Guaraí, Guaraí-TO, Brasil. darcbiomedica@gmail.com

2 Especialista em Avaliação Escolar - Língua Portuguesa pela Cesgranrio, GuaraíTO, Brasil.

3 Bacharel em Enfermagem pelo Centro Luterano de Palmas / Universidade Luterana do Brasil, Palmas-TO, Brasil.

4 Doutora em Ciências pela Universidade Federal de Lavas, Lavras-MG, Brasil.

Recebido em: 15/05/2020 - Aprovado em: 15/06/2020 - Publicado em: 30/06/2020

DOI: 10.18677/EnciBio_2020B11

\begin{abstract}
RESUMO
A massagem pode trazer benefícios clínicos para os portadores de diversas doenças, como exemplo, as condições clínicas causadas pelo estresse. O presente trabalho buscou realizar uma revisão narrativa da literatura sobre os benefícios de diferentes técnicas de massagens, mais especificamente das massagens terapêuticas. Buscou-se descrever o alívio e cura proporcionados ao paciente, destacando-se as diversas vantagens de cada uma das técnicas e sua capacidade em proporcionar bem-estar físico, mental e melhorar a qualidade de vida de pacientes que sofrem de patologias.
\end{abstract}

PALAVRAS-CHAVE: estética, manipulações musculoesqueléticas; qualidade de vida

\section{PHYSICAL AND MENTAL BENEFITS OF THERAPEUTIC MASSAGE}

\begin{abstract}
Massage can bring clinical benefits to patients with several diseases, such as clinical conditions caused by stress. The present work sought to carry out a narrative review of the literature on the benefits of different massage techniques, more specifically therapeutic massages. We sought to describe the relief and cure provided to the patient, highlighting the various advantages of each of the techniques and their ability to provide physical and mental well-being and improve the quality of life of patients suffering from pathologies.
\end{abstract}

KEYWORDS: musculoskeletal manipulations; aesthetics; quality of life

\section{INTRODUÇÃO}

A massagem terapêutica produz inúmeros benefícios, sendo capaz de proporcionar bem-estar físico e mental aos pacientes que a utilizam continuamente (CANÇADO, 2017). Inúmeros são os benefícios da massagem, logo, além do relaxamento do corpo e da sensação de bem-estar, incluem o controle do estresse; a diminuição da ansiedade; o alívio da tensão e das dores musculares; uma significativa melhora da circulação sanguínea; o aumento da elasticidade da pele e da imunidade; a diminuição da pressão arterial, no caso de pacientes hipertensos; o alívio de dores de cabeça; a redução do cansaço; a estimulação e o equilíbrio do 
trato gastrointestinal; a melhora na eliminação de toxinas e resíduos metabólicos e a diminuição da insônia (CEZIMBRA, 2009).

Além disso, estudos neurocientíficos apontam para os benefícios do contato entre a pele do paciente, o maior órgão do corpo humano, com a pele do massagista, enquanto as mãos deslizam sobre o corpo do outro e desencadeiam transformações em todo o organismo, trazendo bem-estar físico e mental (CEZIMBRA, 2009). Este mesmo autor afirma que esses benefícios estão diretamente ligados ao tato, primeira linguagem materna apreendida na infância, que acessa o afeto e os sentimentos conscientes ou inconscientes, promovendo o bemestar.

Por outro lado, além da relação afetiva, o toque permite uma investigação tecidual importante realizada pelo massoterapeuta que, ao tocar o paciente, poderá identificar possíveis lesões na epiderme, como: verrugas irregulares, psoríases, herpes-zorter entre outras disfunções da pele que precisarão de maior investigação médica (CARVALHO; ALMEIDA, 2018).

Existem diversos tipos de massagem, que atuam de diferentes formas para proporcionar os benefícios desejados, conforme os objetivos do paciente ou a indicação clínica para a recuperação ou tratamento de patologias pré-existentes (CANÇADO, 2017). Alguns tipos são bastante conhecidos, como por exemplo a drenagem linfática, que auxilia diretamente em tratamentos de beleza. Por outro lado, o shiatsu, a shantala, a massagem sueca e a ayurvédica caracterizam-se por proporcionarem relaxamento. Já o Tui-Ná, An-Mo, o Do-In, a Thai Massage, o BanFá, a Lomi Lomi, a quick massage, a quiropraxia, a massagem miofascial e a massagem desportiva são comumente utilizadas para o tratamento de dores de origem musculoesquelética, sendo essa apenas uma de suas inúmeras funções (CEZIMBRA, 2009).

De acordo com Carvalho e Almeida (2018), a massagem libera processos químicos no organismo, capazes de reestabelecer a imunidade natural humana, a partir da restauração do humor, reequilibra as funções vitais, que podem desencadear estágios de dor física e mental. Cabe resultar que cada organismo humano reage de diferentes formas às manipulações musculoesqueléticas, desencadeando processos e produção de substâncias que podem atuar na recuperação, no bem-estar físico e mental, com reflexos positivos na saúde do paciente (KIT, 2008).

Entretanto, a massoterapia deve trabalhar em conjunto com a medicina tradicional. Desse modo, será possível proporcionar melhores resultados nos tratamentos dos pacientes. Esta tem como objetivo principal o alívio da dor nas dores de ordem musculoesqueléticas, mas pode prevenir doenças, equilibrar as funções do organismo e assim diminuir o estresse, melhorar a circulação sanguínea e algumas disfunções (CARVALHO; ALMEIDA, 2018). Diante do exposto, o presente estudo teve como objetivo realizar uma revisão narrativa da literatura sobre os benefícios de diferentes técnicas de massagens terapêuticas, ressaltando-se sua aplicabilidade no tratamento de patologias comuns.

Foi realizada uma revisão narrativa da literatura, com buscas nas bases de dados: SciELO, Periódicos da CAPES e Google Acadêmico, de trabalhos publicados entre 2012 e 2020, nos idiomas: português, espanhol, chinês e inglês. Foram utilizados os descritores: manipulações musculoesqueléticas, massagem estética e qualidade de vida, combinados à massoterapia, para que a busca ficasse mais objetiva - em inglês, segundo o Medical Subject Headings (MeSH), e em português, conforme os Descritores em Ciências da Saúde (DeCS). A busca 
dos artigos que compuseram esse estudo foi realizada entre os meses de fevereiro e maio de 2020. Foram incluídos apenas os artigos com disponibilidade de texto completo e originais, além de obras completas sobre a origem da massoterapia, suas técnicas e benefícios.

\section{ORIGEM E CONCEITOS DA MASSOTERAPIA}

Desde os primórdios da civilização, a massagem é utilizada no convívio humano, por isso é considerada uma prática milenar de melhoria do bem-estar físico. Na antiguidade, era considerada como forma de prevenção de infecções pelos egípcios, hindus, gregos, romanos, chineses e japoneses (WANG, 2013). Conforme Cezimbra (2009), as origens da massagem remontam o período préhistórico, quando o homem de forma instintiva tocava no local de dor com o objetivo de contê-la e a fricção que exercia no local, promovia alívio ao toque.

Cada civilização ou cultura desenvolveu estilo próprio e práticas de massagens diversas. Muitas, ainda hoje são ensinadas e praticadas como arte e, também, como ciência em pleno estágio de desenvolvimento (KIT, 2008), tanto em cursos de graduação, como em cursos profissionalizantes (GASPAROTTO et al., 2018).

Sabe-se que a origem da palavra "massagem" vem do grego e significa "amassar". Porém, inicialmente, esta foi utilizada pelos chineses como "Cong Fou", há aproximadamente 2.700 anos a.C (SILVA et al., 2015). O nome "massagem" ganhou maior significado medicinal, após Hipócrates empregar o termo "anatripisis" (friccionar pressionando os tecidos) para se referir às propriedades terapêuticas das manipulações musculoesqueléticas (WANG, 2013).

Por outro lado, a palavra "massoterapia", em um contexto latino, vem da união do termo "masso" que significa "massagem" e "therapia", cujo significado é "tratamento". Esta, desde o princípio, tem como base funcional e clínica o benefício do relaxamento, ao passo que melhora a mecânica do organismo físico, o sistema neural, a fisiologia e a química que se relaciona aos diversos fatores emocionais (COSTA; SOUZA, 2017).

Atualmente a massoterapia agrupa técnicas tradicionais e contemporâneas, cujos métodos não invasivos, são aplicados para identificar e tratar doenças que desequilibram o bem-estar físico e mental de pacientes, ao passo que interferem significativamente no sistema imunológico destes (CARVALHO; ALMEIA, 2018). Assim, no contexto em que se encontra inserida, a massagem terapêutica é utilizada para diversas finalidades, tanto curativas, como promotoras de bem-estar físico ou beleza aos pacientes (LEDUC; LEDUC, 2000).

As massagens podem ser subdivididas em diversos tipos, dentre estas, com maior destaque: (a) a desportiva, utilizada por fisioterapeutas com a finalidade de recuperação de lesões musculares; (b) a relaxante, que promove o relaxamento físico e mental dos pacientes, visando o alívio do estresse provocado pelo dia a dia; (c) a estética, que busca dar alívio para as dores e expressões faciais, ajudando, inclusive, no rejuvenescimento, sendo utilizada também para o tratamento da celulite, das estrias e da gordura localizada, à medida em que auxilia no combate à retenção de líquidos; (d) a terapêutica, usada para proporcionar alívio das dores musculares e ligamentos, além de auxiliar a cura de certas doenças (LEDUC; LEDUC, 2000).

Nesse sentido, percebe-se em que cada técnica se desenvolveu, baseada em conhecimentos antigos tradicionais, para prestar um benefício distinto ao paciente. Mas numa perspectiva moderna impôs-se a necessidade de aperfeiçoamento 
dessas técnicas, para acompanharem os avanços das ciências médicas e se aprimorarem rumo às necessidades da prática em saúde (CANÇADO, 2017).

Portanto, as técnicas massoterápicas descritas, algumas milenares, de origem oriental e outras ocidentais, de origem mais recente, como a drenagem linfática, o shiatsu, o Tui-Ná, o Ban-Fá, An-Mo, a Ayurvédica, a Shantala, o Do-In, a Thai Massage, o Lomi Lomi, a massagem sueca, a drenagem linfática, a quiropraxia, a massagem desportiva, a quick massagem e a massagem miofascial são importantes para reequilibrar a energia do organismo e ajudá-lo a se recuperar de patologias pré-existentes ou prevení-las, por meio do aumento da imunidade tecidual (CARVALHO; ALMEIDA, 2018).

\section{OS BENEFÍCIOS FÍSICOS E MENTAIS DAS TÉCNICAS DE MASSOTERAPIA - Shiatsu}

O Shiatsu é uma técnica terapêutica bastante conhecida e muito comum em praias e parques no Brasil. Esta equilibra mente e corpo, por meio da fricção com a ponta dos dedos ou a planta das mãos, em determinada região do corpo. Essa técnica permite ao paciente um aumento de energia e consciência sobre si e proporciona considerável melhoria no funcionamento dos órgãos, podendo estender seus benefícios musculoesqueléticos, também aos sistemas digestivo e nervoso (CEZIMBRA, 2009).

A técnica do shiatsu promove estimulação ao sistema nervoso, quando possibilita a liberação de endorfinas, proporcionando bem-estar e relaxamento, devido à redução das ondas cerebrais. Além disso, trata-se de um recurso manual não invasivo, que atua proporcionando melhoria na circulação sanguínea e linfática, melhorando o metabolismo, aliviando tensões e proporcionando bem-estar físico e mental (FONTES; SILVA, 2017).

O shiatsu tem sido utilizado no tratamento da fibromialgia, doença de caráter idiopático, que é caracterizada por dor intensa na musculatura, ligamentos e tendões (COSTA; SOUZA, 2017). De acordo com Costa e Souza (2017), a fibromialgia atinge majoritariamente mulheres, entre 30 a 60 anos, sendo o sucesso no tratamento alcançado por meio de uma associação de estratégias farmacológicas e não farmacológicas, dentre estas, a massagem.

Estudo de Caurio et al. (2019), enumerou os benefícios da massagem no tratamento da fibromialgia, sobre o shiatsu foi verificado alívio da dor após as sessões, totalizando 10, mas além dessa técnica experimentou outras, sobre as quais, consideraram que há pouca diferença dos benefícios proporcionados para a melhoria dessa patologia, já que os resultados benéficos podem ser alcançados por mais de uma técnica massoterápica.

No entanto, Cezimbra (2009) alerta para o uso indiscriminado dessa técnica em pacientes reincidentes de traumas recentes, sintomas de cefaleia e dores na coluna, sem a adequada avaliação das condições clínicas e acompanhamento médico, pois pode predispor a graves efeitos colaterais como a hemiplegia, paraplegia ou mesmo a morte do paciente.

\section{- Tui-Ná}

A Tui-Ná é caracterizada por movimentos médios a vigorosos, aplicados por partes do corpo, como: dedos, mãos, punhos, antebraço e joelhos, com o objetivo de estimular o organismo a se curar. Assim, sua função é equilibrar o fluxo de energia do organismo, sendo eficaz no tratamento da dor (FONTES; SILVA, 2017). Para Mercati (2000), desde o nascimento, o cuidado com o bebê demonstra a importância 
de tocar e acariciar para acalmar, por isso, uma versão mais leve dessa técnica se mostra benéfica ao crescimento de crianças saudáveis e inteligentes.

Essa técnica trata diretamente a dor e a ansiedade, contribuindo sistematicamente para a restauração do sono, em casos de dissonia em crianças desde o nascimento e, mais notadamente, em jovens durante o período escolar (FREITAS et al., 2017). Em estudo de Freitas et al. (2017) foram descritos dois casos de crianças em transtornos do desenvolvimento psicológico, nos quais a criança tem oportunidade de aprender, mas não consegue; além dos distúrbios de aprendizagem, como a dislexia e a discalculia. Além disso, consideraram o sono como fator importante para melhorar a aprendizagem de modo geral. Finalmente, concluiram que a massagem permitiu melhorar o sono e, a partir disso, diminuiu os déficits de atenção - comuns da fase escolar - e melhoraram tanto o comportamento, como o desempenho escolar das duas crianças estudadas.

Além disso, Kurebayashi et al. (2016) descreveram as vantagens da aplicação de massagens relaxantes na reabilitação de pacientes hospitalizados na América do Norte. A massagem tornou-se uma ferramenta interessante aos profissionais de enfermagem, para tratar os pacientes que apresentavam quadros passageiros ou permanentes de dor, ansiedade e tensão, melhorando consideravelmente os quadros de saúde, ainda que irreversíveis.

\section{- Ban-Fá}

A técnica chinesa Ban-Fá manipula a coluna vertebral, músculos e articulações para promover um efeito regulador do organismo e, assim, proporcionar o alívio de dores e melhoria das funções motoras, melhorando a qualidade do funcionamento corporal e a qualidade de vida. Faz parte das técnicas chinesas de manipulações vertebrais, incluídas no Tui-Ná, sendo, portanto, uma variação com técnicas mais vigorosas (FONTES; SILVA, 2017).

Essa técnica tem sido utilizada no tratamento da fibromialgia, em que os pacientes acometidos relatam dor musculoesquelética crônica e difusa, locais sintomáticos de grande dor e sensibilidade, denominados pontos dolorosos. A literatura relata melhoria da circulação, relaxamento e analgesia em pacientes portadores dessa doença, proporcionados pela manipulação das vertebras, músculos e articulações (COSTA; SOUZA, 2017).

\section{- An-Mo}

A massagem An-Mo é outra especialidade chinesa, a qual considera os meridianos e pontos de acupuntura do corpo, faz parte da Medicina Tradicional Chinesa e foi estabelecida por volta de 1300 a.C., na China Central (AUTEROCHE; NAVAILH; 1993). A An-Mo é aplicada diretamente em áreas reflexas, para tonificar e estimular o corpo e a mente, cujo objetivo é circular e reequilibrar as energias (AUTEROCHE; NAVAILH; 1993). Essa técnica, por ser antiga, deu origem a outras técnicas mais modernas, como relata Silva e Zarbato (2017) sobre a quick massage.

\section{- Ayurvédica}

A massagem ayurvédica é uma técnica muito utilizada por médicos e terapeutas, conhecida como a mais antiga técnica de massagem natural, tendo sido criada há mais de cinco mil anos (JANSEN-SCHULZE, 2009). Esta, é amplamente utilizada na Índia, sendo aplicada a pacientes de todas as idades.

Dentre os benefícios da técnica ayurvédica, cita-se o estreitamento do relacionamento entre pais e seus bebês, bem como a estimulação do 
desenvolvimento físico e emocional da criança e da produção de prolactina pelo organismo materno, com benefícios galactagogos (JANSEN-SCHULZE, 2009).

Carvalho e Almeida (2018), afirmam que a massagem ayurvédica é muito eficaz no combate ao estresse, quando oxigena os tecidos que retém a sobrecarga do organismo humano em estágio estressante. Além disso, recupera nutrientes perdidos e repara o cansaço progressivo, provocado pela perda de nutrientes e pela sobrecarga da falta de oxigenação tecidual. Por isso, a aplicação dessa massagem, que simboliza amparo psicológico, tanto é eficaz durante o período de cólicas neonatais, como é muito importante durante a primeira dentição infantil, pois é extenuante o estresse gerado no organismo do bebê, durante essa fase (JANSENSCHULZE, 2009).

Uma questão importante sobre essa massagem é a preparação. É preciso entender que dar segurança ao bebê para a aplicação da massagem é essencial para se obter sucesso. O óleo, a posição, a forma de tocar de maneira intuitiva no bebê, permitirão assegurar naturalidade ao toque e, assim, atingir o relaxamento desejado, por meio das manobras de alongamento que a técnica proporciona (JANSEN-SCHULZE, 2009).

Por suas características relaxantes e ação direta sobre a diminuição dos sintomas de estresse em geral, a massagem ayurvédica, também pode agir diretamente sobre a fibromialgia, diminuindo os quadros sintomáticos de dores leves a intensas (GONDIM; ALMEIDA, 2018).

Caurio et al. (2019) realizaram um estudo com um grupo de pacientes, nos quais administraram a massagem ayurvédica em 13, dos 25 voluntários fibriomiálgicos, mas não realizaram massagem em 12 dos demais pacientes selecionados para o estudo, o intuito foi verificar os benefícios dessa técnica sobre a dor fibromialgica, como resultado, observaram que houve considerável melhora da sintomatologia da dor naqueles que receberam a massagem, em detrimento daqueles que não receberam.

\section{- Shantala}

Além da massagem ayurvédica, bastante indicada para bebês, a técnica da shantala é mais uma alternativa de massagem infantil. Estudo de Cezimbra (2009) afirma que esta técnica, utilizada em bebês a partir da terceira semana após o nascimento, tem por função aliviar as cólicas e aumentar o vínculo com os pais. Dessa forma, esta ajuda o bebê a se sentir novamente dentro do útero da mãe, onde suas necessidades eram plenamente atendidas, o que trazia uma sensação de completude à criança. Assim, a massagem ajuda o neonato a se adaptar e superar as dificuldades pós-natais.

Segundo a pesquisa de Ribeiro-Lima e Cavalcante (2019), a massagem infantil, shantala tem o papel de fortalecer vínculos familiares, os quais muitas vezes são distanciados por causa da vida profissional dos pais. Então essa técnica, sob um aspecto multissensorial, pode restabelecer a ligação entre pais e filhos, propiciando um contato que reduz o estresse das crianças, provocado pelo compartilhamento coletivo de ambiente, como: creches e escolas, nos quais a figura conhecida, pai ou mãe, não está presente.

- Do-In

A técnica do Do-In, conforme Cançado (2017), pertence à medicina tradicional chinesa e é bastante utilizada para o tratamento de patologias diversas. Trata-se de 
um método de massagem que, por meio de estímulos à circulação da energia vital, é capaz de amenizar dores e proporcionar o bem-estar (MARTINS, 2014).

Além disso, a técnica é própria para a autoaplicação, mas pode também ser aplicada por outra pessoa. Utiliza a pressão dos dedos das mãos, em pontos específicos do corpo humano, com objetivo de trazer alívio, prevenir, identificar e tratar enfermidades dolorosas, de diversas origens físicas e problemas psicológicos relacionados ao estresse (CANÇADO, 2017).

O Do-In, conforme o conceito chinês, considera o organismo de forma dinâmica como o universo, sendo, portanto, regido conforme as leis naturais, e contendo energia como matéria sólida e viva, que flui. Para o Do-In, o organismo celular precisa estar em sintonia com o que está ao seu redor (CANÇADO, 2017).

Outro benefício clínico da massagem Do-In, conforme Jesus (2018), seria na diminuição do desconforto comumente relatado por gestantes, dentre eles: dor nos membros inferiores, insônia, fadiga corporal e dores lombares. A conclusão do trabalho realizado por Jesus (2018) evidencia os benefícios dessas técnicas complementares para a saúde gestacional e atesta, tanto a necessidade de que o profissional enfermeiro conheça tais técnicas, como a pouca aplicação dessa temática na abordagem pré-natal. Além disso, Monteiro et al. (2018) demonstraram em seu estudo a importância da massagem tanto no pré, quanto no pós-parto das gestantes para ajudar no desconforto provocado pelo aumento de volume abdominal e da má circulação.

Assim, essa modalidade de massagem simboliza, tanto para Cançado (2017) como Jesus (2018), que as terapias complementares de origem chinesa demonstram respeito ao indivíduo como um todo, distribuído por corpo, mente e espírito, gerando benefícios ao organismo de cura e saúde, quando todas as partes estão interligadas e a energia que o rodeia é mantida ou reestabelecida.

\section{- Thai Massage}

O Nuad Phaen Boran ou Thai Massage é uma terapia curativa Tailandesa, com o objetivo de reestabelecer o equilíbrio corporal, realizada com os pés, joelhos, polegares, palmas e cotovelos (SILVA et al., 2015). A técnica tem objetivo energético, pois utiliza manobras corporais que envolvem torções, compressões e alongamentos profundos, no intuito de liberar pontos da energia vital e que estejam com o trânsito bloqueado. Além disso, promove aumento da flexibilidade dos músculos e articulações (SILVA et al., 2015).

Essa técnica é bastante utilizada por atletas de luta Muay-Tai, para alívio da dor e da fadiga muscular, promovendo maleabilidade e extensibilidade tecidual e articular, além de estimular as funções viscerais e autonômicas (SILVA et al., 2015). Os benefícios da Thai massage incluem, ainda, melhora significativa de dores nas costas associadas à lombalgia, quadros de incapacidade com flexibilidade reduzida (SILVA et al., 2015).

Segundo Laosee et al. (2020), a dor lombar, mais especificamente em idosos, está relacionada a gatilhos miofasciais, sendo que a Thai massage é uma técnica de massoterapia capaz de desativar este gatilho, aumentar a flexibilidade e diminuir a incapacidade causada pela lombalgia, bem como promover analgesia aos quadros de dor do paciente. 


\section{- Lomi Lomi}

A massagem Lomi Lomi é uma técnica massoterápica relaxante, de origem havaiana, que se diferencia das técnicas orientais, pois trabalha o corpo do paciente sem usar os dedos, utilizando, portanto, pontos de pressão (STONE, 2010). Segundo Stone (2010), a massagem Lomi Lomi é também denominada circulatória, uma vez que tem por função mover os fluidos corporais, a fim de deixar a energia circular e aliviar a tensão, trabalhando o alongamento e as extremidades articulares. A autora considera ainda que esse tipo de massagem pode ser aplicado em movimentos vigorosos, melhorando bastante as dores articulares e a circulação sanguínea.

Para os havaianos a massagem Lomi Lomi constitui uma forma importante de conhecer o outro, de se ligar a ele e de se reorganizar psiquicamente, para agir melhor diante da vida, ou seja, esta é responsável pela melhora da qualidade de vida psicossocial das pessoas que a utilizam (BERGER, 2020).

\section{- Massagem Sueca}

A Massagem Sueca ou Massagem Clássica é considerada a base para as demais técnicas de massagens ocidentais, e ficou conhecida pelo termo relaxante, seu nome comercial. Consiste na utilização de movimentos suaves e deslizantes, promovendo alongamento e auxiliando na redução do estresse e da ansiedade no paciente. Melhora a tensão e acentua a flexibilidade dos tecidos e músculos do corpo, promovendo relaxamento e bem-estar (SILVA et al., 2015). Na Suécia, durante o século XIX, essa massagem passou a ter como fundamento básico: recuperar músculos, articulações e ossos (CARVALHO; ALMEIDA, 2018).

Por tudo isso, afirmam Carvalho e Almeida $(2018$, ) a consistente melhora na circulação sanguínea, tendo em vista a potencialização do sistema linfático. Nessa análise sobre os benefícios da massoterapia, estes autores apresentam ainda os resultados para os indivíduos que frequentemente utilizam-na, alguns vão desde a melhora da imunidade, bem como a diminuição da fadiga, da agitação mental, da insônia e ainda proporciona aumento da flexibilidade e relaxamento dos nervos.

Por outro lado, a massagem sueca também pode ser utilizada por pacientes em tratamentos de câncer. Conforme afirmam Rodríguez-Mansilla et al. (2017), combina-se a utilização de movimentos mais vigorosos para aplicá-los na reabilitação e tratamento psicológico, com efeito calmante.

\section{- Drenagem Linfática}

A Drenagem Linfática Manual ou Drenagem Linfática consiste numa técnica de pressão suave a moderada com as mãos, para melhorar a atividade e as funções do sistema linfático e venoso do organismo humano, cujos movimentos se fundamentam suaves, em direção centrífuga e moderados, em direção centrípeta (CARVALHO; ALMEIDA, 2018). No entanto, movimentos mais vigorosos também fazem parte dessa massagem, porém não devem ser aplicados no período póscirúrgico. Os movimentos, quando não executados por profissional capacitado, em ritmo desequilibrado e/ou com pressão tecidual excessiva, podem provocar lesões e rompimento de vasos sanguíneos, propiciando 0 surgimento de manchas arroxeadas e queixas de dor pelo paciente (LEDUC; LEDUC, 2000). É recomendada, portanto, para a redução de medidas e a melhora do aspecto da pele, em pacientes com retenção de líquidos e toxinas, que serão eliminados pelo corpo.

Atualmente, a drenagem pode ser realizada por profissionais que pretendem potencializar ainda mais os resultados da drenagem, por meio de aparelhos 
específicos. Essa técnica promete resultados na melhoria dos contornos corporais, contribuindo para uma aparência melhor (BATISTA et al., 2017). A drenagem atua também para reverter quadros de lipodistrofia localizada, ou seja, um acúmulo de gordura localizada ocasionado por diversos fatores, mas que com a massagem modeladora (MACHADO et al., 2017), associada à tecnologia de ultrassom, tornará possível aumentar a circulação vascular periférica e permitir a eliminação de toxinas e da gordura, com consequente perda de peso e de medidas (MACHADO et al., 2020).

Além disso, a drenagem modeladora é essencial no pós-operatório de cirurgias plásticas de abdominoplastia e lipoaspiração, pois diminui o inchaço provocado pelo processo inflamatório pós-cirúrgico (MACHADO et al., 2017). Batista et al. (2017) afirmam ainda que a drenagem auxilia no alívio dos sintomas do período pré-menstrual, do inchaço gestacional e auxilia na redução da celulite. Por fim, essa técnica também pode ser aplicada na face, reduzindo sinais de envelhecimento precoce.

\section{- Quiropraxia}

De nome derivado do grego kheir, que significa mão e práxis, prática, a quiropraxia simboliza o tratamento com as mãos. Surgiu no final do século XIX e pode propiciar, pela manipulação das vértebras, o alívio das dores na coluna, redução das enxaquecas, bem como das dores de cabeça comuns (CEZIMBRA, 2009).

Essa técnica é reconhecida pela Organização Mundial de Saúde (OMS) e é aplicada por profissional capacitado em quiropraxia, que utiliza as mãos para diagnosticar, tratar e prevenir problemas no sistema neuro-músculo-esquelético (FERREIRA et al., 2020). A técnica constitui em aplicar no paciente, movimentos precisos e específicos na região da dor, chamados de ajustes quiropráticos, que levam ao equilíbrio do sistema neuro-músculo-esquelético. Além disso, essa técnica tem se demonstrado eficaz no tratamento da dor lombar crônica, que impede a natural regeneração tecidual (FILHO et al., 2019).

Estudo de Filho et al. (2019) destaca que a inflamação provocada pela hérnia de disco, cujo processo inflamatório, provocado pelo rompimento do anel fibroso da coluna vertebral, pode ser amenizada com as técnicas de quiropraxia; reestabelecendo os movimentos da coluna vertebral e membros periféricos, e reduzindo quadros de dor.

\section{- Massagem desportiva}

A Massagem Desportiva é utilizada por atletas, amadores ou profissionais, para manutenção e reabilitação dos tecidos moles do corpo humano, como por exemplo músculos, ligamentos e tendões (ROCHA et al., 2019). São vários os seus benefícios, dentre eles a prevenção de lesões, por meio do relaxamento e da melhor circulação sanguínea; melhoria do sono; redução de aderências, edemas e processos inflamatórios provocados pela lesão física (ABREU et al., 2012).

Assim, a crioimersão, mais conhecida como banheira de gelo, proporciona melhora nas lesões e dor de efeito tardio. Rocha et al. (2019), consideram que essa melhora poderá ser potencializada, quando associada a técnica de massagem desportiva, a qual reduz a dor, ao passo que diminui a frequência cardíaca, promovendo relaxamento ao desportista durante o tratamento. Além disso, pode promover significativa melhoria do controle motor, uma vez que tais efeitos parecem estar relacionados aos efeitos analgésicos (ABREU et al., 2012). 


\section{- Quick Massage}

A Quick Massage, conforme Silva e Zarbato (2017) é uma massagem rápida, que alia técnicas de duas massagens orientais, o Shiatsu e o An-Mo, podendo ser realizada no trabalho, com o paciente sentado, tendo como função promover o relaxamento, além de diminuir condições de dor de ordem musculoesquelética.

Segundo Oliveira et al. (2017), essa massagem também tem por função diminuir as doenças provocadas pelo estresse, o qual está associado à liberação de hormônios que, além de alterarem vários aspectos da fisiologia, possuem ainda efeito modulador das defesas do corpo, que debilitam a saúde do paciente ou dificultam suas relações e, por afetarem diretamente o humor, provocam também baixo rendimento no trabalho e outros males.

Silva e Zarbato (2017) destacam ainda que, para melhor entender os benefícios da quick massage, faz-se necessário avaliar o ambiente de trabalho, observando os fatores de risco, tanto físicos, como psicossociais e, a partir disso, entender que a massagem pode auxiliar a reorganizar a capacidade de produção do paciente, o qual vive em meio a multitarefas e à prática de atividades laborais de esforço repetitivo.

\section{- Massagem Miofascial}

Este tipo de massagem é caracterizado pelo toque terapêutico sobre músculos e nervos e, por isso, auxilia na diminuição das dores corporais. É aplicada sobre o músculo tensionado, sendo realizada em tecidos moles, não em nervos e ossos (CEZIMBRA, 2009).

Sua técnica flexora, extensora e cruzada, permite utilizar a biomecânica do paciente a favor de um bom resultado, pois é possível reconhecer os sinais da região dolorida e durante a massagem, identificar que outras áreas também necessitam de atenção (CEZIMBRA, 2009).

Estudo comparativo de Sousa et al. (2015), apresenta 16 mulheres, entre 42 e 48 anos, que sofrem com cefaleia tensional crônica, caracterizada por dor bilateral, frontal, temporal, fronto-temporal, de pressão ou peso, a qual tem início esporádico com duração de minutos, podendo chegar a dias. Foram utilizados fármacos, associados a terapias complementares, entre elas a massagem miofascial. Os resultados mostraram que no grupo com associação do tratamento farmacológico à terapia complementar a dor ao toque era aumentada, mas com progressiva diminuição durante o tratamento.

Os resultados apresentados por Sousa et al. (2015) se apoiam na teoria de Cezimbra (2009), de que as fibras musculares promotoras de movimento têm suas funções mecânicas danificadas pela tensão em excesso provocada pela dor, mas o estímulo neurológico promovido pela massagem descontrai a tensão e possibilita a recuperação natural dos movimentos perdidos.

Cezimbra (2009) relata ainda diversos outros benefícios da massagem miofascial em pacientes com queda de cabelo, circulação sanguínea de membros inferiores, melhora da dor em paciente com desequilíbrio biomecânico ou dor nas articulações. Diante do exposto, observa-se ainda que os benefícios físicos e mentais propiciados pela massoterapia também estão associados à melhora da imunidade, uma vez que o toque das mãos na pele ativa linfócitos $T$, permitindo efeito calmante e desestressante, à medida que diminui também a ansiedade (CARVALHO; ALMEIDA, 2018). Como consequência do alívio do estresse, observase ainda melhora de quadros provocados por baixa imunidade, como úlceras, má 
digestão, doenças infecciosas, distúrbios gastrointestinais, insônia, dores de cabeça, ansiedade e depressão (CANÇADO, 2017).

Além disso, terapias complementares podem auxiliar pacientes em períodos pós-cirúrgicos, a eliminarem edemas, reativando a circulação, eliminando as toxinas que impedem uma adequada recuperação (BATISTA et al., 2017). Conforme postulam Gasparotto et al. (2018), surge a necessidade do compartilhamento e integração dos saberes sobre as práticas integrativas e complementares, entre profissionais da área da saúde, no intuito de aumentar as possibilidades de tratamentos a serem oferecidos aos portadores de condições crônicas para obtenção de melhores resultados nos tratamentos convencionais e melhoria da qualidade de vida na saúde humana.

\section{CONSIDERAÇÕES FINAIS}

Desde as origens da massoterapia, nos primórdios da civilização, percebeuse que a sua prática é utilizada para promover bem-estar àqueles que a utilizam. Das diversas técnicas existentes, muitas são usadas ainda hoje e outras evoluíram para atender às necessidades da vida moderna e de melhoria da qualidade de vida das pessoas. Nesse sentido, os benefícios promovidos pelas diferentes técnicas vão muito além do relaxamento, pois melhoram o funcionamento de todo o corpo, reequilibrando-o e propiciando condições necessárias à recuperação e à cura.

Ressalta-se a importância no diagnóstico médico para a indicação clínica que associe, entre outras possibilidades, práticas integrativas e complementares de saúde, como a massoterapia, ao tratamento convencional.

Uma vez conhecidas e indicadas pelos profissionais de saúde, as técnicas de massagem poderão promover o bem-estar geral dos pacientes e, aliadas à medicina tradicional, figurarem como alternativas importantes ao tratamento de doenças, ou ainda, colaborarem para o aumento da qualidade de vida em processos patológicos agudos e crônicos.

\section{REFERÊNCIAS}

ABREU, M. F.; SOUZA, T. F.; FAGUNDES, D. S. Os efeitos da massoterapia sobre o estresse físico e psicológico. Revista Científica Faculdade de Educação e Meio Ambiente, $\quad$ v. $1, \quad$ n. 3, 2012. Disponível em: http://www.faema.edu.br/revistas/index.php/Revista-FAEMA/article/view/119. DOI: https://doi.org/10.31072/rcf.v3i1.119. Acesso em: 26 abr. 2020.

AUTEROCHE, B.; NAVAILH, P. O Diagnóstico na Medicina Chinesa. Tradução: Zilda Barbosa Antony. São Paulo: Andrei, 1993, 422 p.

BATISTA, A. T. D.; GARCIA, K. V.; COSTA, M. F.; COLOMBI, B. M. Drenagem linfática manual: histórico, métodos e eficácia. Revista Maiêntica, Indaial, v. 1. n. 01, $2017 . \quad$ Disponível em https://publicacao.uniasselvi.com.br/index.php/EIP/article/view/1823. Acesso em: 30 abr. 2020.

BERGER, C.. Ho'oponopono: a antiga prática havaiana da gratidão e do perdão. 1 ed. Pensamento-Cultrix, 2020, $160 \mathrm{p}$.

CANÇADO, J. Do-in: a milenar arte chinesa de acupuntura com os dedos. 50 ed. Ground, 2017. 320 p. 
CARVALHO, R. J.; ALMEIDA, M. A. P. T. Efeitos da massoterapia sobre o sistema imunológico. Revista Multidisciplinar e de Psicologia, v. 12, n. 40, 2018. Disponível em: https://idonline.emnuvens.com.br/id/article/view/1118. DOI: https://doi.org/10.14295/idonline.v12i40.1118. Acesso em: 1 mai. 2020.

CAURIO, E. H. A.; BIAZUS, J. F.; MACIEL, M. B.; OLIVEIRA, L. O. Efeitos das diferentes técnicas de massagem no tratamento da dor fibromiálgica: uma revisão integrativa. Disciplinarum Scientia, série Ciências da Saúde, v. 20. n. 2, 2019. p. 391-398. https://periodicos.ufn.edu.br/index.php/disciplinarumS/article/view/2675. Acessado em: 26 abr. 2020.

CEZIMBRA, M. Bem-Estar na Palma das Mãos: a cultura da massagem do oriente ao ocidente. Rio de Janeiro: Senac Nacional, 2009. 160 p.

COSTA, F. R. B.; SOUZA, L. C. Efeitos da hidroterapia associado a massoterapia em pacientes portadores da fibromialgia. Revista Visão Universitária, v. 2. n. 1. 2017. http://www.visaouniversitaria.com.br/ojs/index.php/home/article/view/114/102. Acesso em: 2 mai. 2020.

FERREIRA, S. K. S.; CUNHA, I. P.; MENEGHIM, M. C.; DE CHECCHI, M. H. R. Política nacional de práticas integrativas e complementares no sistema único de saúde: reflexões sobre as práticas integrativas e complementares. Revista FAIPE, v. 10, $\quad$ n.1, 2020. Disponível em: http://www.revistafaipe.com.br/index.php/RFAIPE/article/view/144. Acesso em: 3 mai. 2020.

FILHO, J. E. S. S.; SANTOS, E. R.; ALMEIDA, M. R. M. Quiropraxia: abordagem fisioterapêutica associada ao tratamento de hérnia discal lombar. Revista EEDIC, $\mathrm{V}$. 6, 2019.2 Disponível em: http://publicacoesacademicas.unicatolicaquixada.edu.br/index.php/eedic/article/view/ 3802. Acesso em: 29 abr. 2020.

FONTES, J.; SILVA, R. Tui Na - Manipulações na Massagem Chinesa. 1 ed. Catarina Sabino, 2017. 93 p.

FREITAS, M. S.; NASCIMENTO, C.; OLIVEIRA, C. C. Efeitos da massoterapia na qualidade do sono e desempenho escolar: estudo de dois casos. Ensaios USF, v. 1. n. $1.2017 . \quad$ Campinas, Disponível em http://ensaios.usf.emnuvens.com.br/ensaios/article/view/49/10. Acesso em: 2 mai. 2020.

GASPAROTTO, L. P. R.; BONTORIN, C. M. S.; ALVES, T.; FOSS, J. A. Impacto da Iniciativa Extensionista na Comunidade Local e na Formação do Estudante do Curso Técnico em Massoterapia: Projeto Mãos Itinerantes - Massoterapia em Eventos. Revista Brasileira da Educação Profissional e Tecnologia, 2018. Disponível em : http://www2.ifrn.edu.br/ojs/index.php/RBEPT/article/view/7025/pdf.

DOI: 10.15628/rbept.2018.7025. Acesso em: 4 abr. 2020. 
GONDIM, S. S.; ALMEIDA, M. A. P. T. Os efeitos da massagem terapêutica manual em pacientes com a síndrome da fibromialgia. Revista Multidisciplinar e de

Psicologia, v. 12, n. 39, 2018. Disponível em: https://idonline.emnuvens.com.br/id/article/view/994.

DOI: https://doi.org/10.14295/idonline.v12i39.994. Acesso em: 3 mai. 2020.

JANSEN-SCHULZE, Y. Massagem ayurvédica para bebês. Tradução: Inês Antônia Lohbauer. Osasco -SP: Novo Século Editora, 2009. 174 p.

JESUS, A. C.; DRAGO, L. C. Os benefícios das terapias complementares para o cuidado no período gestacional - uma revisão integrativa. REUNI, Unisal, coleção Estética e Bem Estar - Tubarão, 2018. Disponível em: http://www.riuni.unisul.br/handle/12345/5470. Acessado em 6 mai. 2020.

KIT, W. K. Chi kung (QIGONG): para a saúde e a vitalidade. 3 ed. Brasil: Pensamento, 2008. 114 p.

KUREBAYASHI, L. F. S.; TURRINI, R. N. T.; SOUZA, T. P. B.; TAKIGUCHI, R. S.; KUBA, G. et al. Massagem e Reiki usados para reduzir o estresse e a ansiedade: ensaio clínico randomizado. Revista Latino-Americana de Enfermagem. v. 24. Ribeirão Preto, $2016 . \quad$ Disponível em: http://www.scielo.br/scielo.php?script=sci_arttext\&pid=S0104-11692016000100434. DOI: https://doi.org/10.1590/1518-8345.1614.2834. Acesso em: 28 abr. 2020.

LAO, T. TAO TE CHING: o livro que revela Deus. 5 ed. Tradução: Huberto Rohden. Martin Claret: São Paulo, 2013. 136 p.

LAOSEE, O.; SRITOOMMA, N.; WAMONTREE, P.; RATTANAPAN, C.; SITTHIAMORN, C. A eficácia da massagem tradicional tailandesa versus massagem com compressa de ervas em pacientes idosos com dor lombar: um estudo controlado randomizado. Terapias Complementares em Medicina, v. 48, 2020. Disponível em: https://www.sciencedirect.com/science/article/pii/S0965229919308702?via\%3Dihub. DOI: https://doi.org/10.1016/j.ctim.2019.102253. Acesso em: 25 abr. 2020.

LEDUC, A.; LEDUC, O. Drenagem Linfática Teoria e Prática. 2 ed. São Paulo: Manole. 2000. 66 p.

MACHADO, A. B. C.; PEREIRA, G. P.; RODRIGUES, G. M.; Fisioterapia e estética: procedimentos com ultrassom. Revista Liberum Accessum, v. 1, n. 2, 2020. Disponível em: http://revista.liberumaccesum.com.br/index.php/RLA/article/view/10/19. Acesso em 23 abr. 2020.

MACHADO, A. T. O. M.; NOGUEIRA, A. P. S.; LAÃO, L. T. S.; SANTOS, B. A.; PINHEIRO, L. M. G. et al. Benefícios da Massagem Modeladora na Lipodistrofia Localizada. v. 11. n. 35. Revista Multidisciplinar e de Psicologia, 2017. Disponível em: https://idonline.emnuvens.com.br/id/article/view/741/1063. Acesso em: 28 abr. 2020. 
MARTINS, E. I. S.; LEONELLI, L. B. Do In, Shiatsu e Acupuntura uma visão chinesa do toque terapêutico. 3 ed. Brasil: Roca, 2014. 296 p.

MERCATI, M. Tui na massagem: para uma criança mais saudável e inteligente. Brasil: Manole, 2000. 96 p.

MONTEIRO, R. A.; CAVALCANTI, H. N. C.; QUEIROZ, N. A.; FURTADO, G. D. Atenção primária no pré e pós-parto em mulheres grávidas em um bairro do nordeste do Brasil. Environmental Smoke, v. 1. $\mathrm{n}$ 1, 2018. Disponivel em http://www.environmentalsmoke.com.br/index.php/EnvSmoke/article/view/14/19DOI: https://doi.org/10.32435/envsmoke.201811168-172. Acesso em: 29 mar. 2020.

OLIVEIRA, G. G.; ANTUNES, E. D.; SANTOS, G. J. B. Massagem laboral (quick massage) na promoção da saúde: estudo quali-quantitativo. Cadernos de Naturologia e Terapias Complementares. v. 8, n. 14, 2019. Disponível em: http://www.portaldeperiodicos.unisul.br/index.php/CNTC/article/download/8459/4655. DOI:10.191177/cnte.v8e14201946-46. Acesso em: 29 abr. 2020.

RIBEIRO-LIMA, T. V.; CAVALCANTE, L. I. C. A massagem infantil como recurso para modulação do estresse em bebês em ambiente de cuidados coletivos. Revista Eletrônica Acervo Saúde, v. 11 n. 1, 2019. Disponível em: https://acervomais.com.br/index.php/saude/article/view/438.

https://doi.org/10.25248/reas.e438.2019. Acesso em: 27 abr. 2020.

ROCHA, L. S.; NUNES, R. D.; REIS, G. R.; JUNIOR, E. B. L. B. Eficácia da crioimersão e massagem desportiva na recuperação de atletas: uma revisão da literatura. Amazônia Science \& Health, v. 7, n. 3, 2019. Disponível em: http://www.ojs.unirg.edu.br/index.php/2/article/view/2786. DOI:10.18606/23181419/amazonia.sci.health.v7n3p74-83. Acesso em: 27 de abr. 2020.

RODRÍGUEZ-MANSILLA， J.; GONZÁLEZ-SÁNCHEZ, B.; TORRES-PILES, S.; MARTÍN, J. G.; JIMÉNEZ-PALOMARES, M. et al. Efeitos da aplicação da massagem terapêutica em crianças com câncer: uma revisão sistemática. Revista LatinoAmericana de Enfermagem, v. 25. Ribeirão Preto, 2017. Disponível em: http://www.scielo.br/scielo.php?script=sci_arttext\&pid=S0104-11692017000100602. DOI: https://doi.org/10.1590/1518-8345.17744.2903. Acesso em: 28 abr. 2020.

SILVA, C. F.; ZARBATO, G. F. Benefícios da quick massagem na dor musculoesquelética relacionado ao trabalho. REUNI, Unisul, 2017. Disponível em: http://www.riuni.unisul.br/handle/12345/4773. Acesso em: 27 de abr. 2020.

SILVA, M. B. V.; ISHIIKAWA, N.; NESSI, A. L. S. Benefícios da massagem antiestresse na recuperação pré e pós luta de atletas de muay thai. Revista FIEP BULLETIN On-line, v. 85, 2015. Acesso em: 20 mar. 2020.

SOUSA, R. C.; SILVA, L. F. B. P.; BARRADAS, L. P. F.; SILVA, C. C.; MATOS, L. K. $B$. L. et al. Efeitos da liberação miofascial na qualidade e frequência da dor em mulheres com cefaleia do tipo tensional induzida por pontos-gatilho. Revista Fisioterapia Brasil, v. 16, n. 3, 2015, p. 231-235. Disponível em: 
http://portalatlanticaeditora.com.br/index.php/fisioterapiabrasil/article/view/80/134 .

DOI: http://dx.doi.org/10.33233/fb.v16i3.80.

STONE, V. J. The World's Best Massage Techniques the Complete Illustrated Guide: Innovative Bodywork Practices from Around the Globe for Pleasure, Relaxation, and Pain Relief. 1 ed. N.C.M.T.: Fair Winds Press, 2010. 256 p.

WANG, B. Princípios de medicina interna do imperador amarelo. Tradução José Ricardo de Amaral Sousa Cruz. São Paulo: Editora Ícone. 2013. 830 p. 